\title{
A adoÇão de filtros e meCanismos de CONTENÇão para os Tribunais SUPERIORES: A VALORIZAÇÃo DA JURISPRUDÊNCIA E A INSTITUIÇÃO DA REPERCUSSÃO GERAL NO DIREITO BRASILEIRO ${ }^{78}$
}

\author{
Adoption of filters and mechanisms of contention for Superior Courts: \\ a valuation of jurisprudence and establishing the general impact on \\ brazilian law
}

Márcio de Sessa

Mestrando UNINOVE. Advogado. Membro do Grupo de Pesquisa/CNPQ "Reforma e Inovação do Poder Judiciário”. E-mail: marciosessa@gmail.com.

Mônica Bonetti Couto

Doutora e Mestre em Direito pela PUC/SP. Professora Permanente do Mestrado em Direito da Universidade Nove de Julho. Líder do Grupo de Pesquisa/CNPQ "Reforma e Inovação do Poder Judiciário". E-mail: monicabonetticouto@yahoo.com.br.

RECEBIDO EM: 10.08.2013

APROVADO EM: 20.12.2013

\section{Resumo}

A explosão de litigiosidade a qual o sistema de justiça brasileiro se submete, denominada crise do Judiciário e, em um recorte menor, crise dos Tribunais Superiores e, em particular, do STF, tornou-se o contexto da necessária adoção de filtros de contenção e da recuperação das funções institucionais de Corte Constitucional e Política ao STF. A finalidade pública, transcendental ao interesse das partes, consolida-se com a tendência de abstrativização dos efeitos do controle difuso de constitucionalidade, aproximando-se, em larga medida, do controle concentrado. A valorização da jurisprudência cumpriu importante função, estimulando a adoção de filtros e mecanismos de contenção, cuja análise se volta para a evolução do papel da jurisprudência e da Repercussão Geral para admissão do recurso extraordinário. No entanto, há que se verificar a utilidade processual que se tem dado a este importante método de racionalização dos trabalhos do Supremo Tribunal para, cotejando com os números oficiais, aferir sua eficácia real. Neste quesito, o objeto de análise foi

\footnotetext{
${ }^{78}$ Este artigo foi escrito com base nas discussões, leituras e trabalhos desenvolvidos no Grupo de Pesquisa/CNPQ "Reforma e Inovação do Poder Judiciário", no âmbito do Programa de Mestrado em Direito da Universidade Nove de Julho.
} 
a Repercussão Geral, cujo resultado, apesar dos esforços teóricos, expõe a (ainda) limitada utilização do filtro e a equivocada exposição dos dados que o justificariam publicamente.

Palavras-chave: Filtros de contenção. Repercussão geral. Papel da JurisprudênCIA.

\section{Abstract}

The explosion of litigation which the Brazilian justice system undergoes called crisis of the judiciary, and a minor cut, the crisis of the Superior Courts and in particular the Supreme Court, became the context of the adoption of necessary filters and containment the restoration of the institutional functions of the Constitutional Court and the Supreme Court Policy. The public purpose, the transcendental interest of the parties, consolidated with the trend of abstrativização the effects of diffuse control of constitutionality, approaching a large extent, the concentrated control. The appreciation of the law played an important role, encouraging the adoption of filters and restraint mechanisms, whose analysis turns to the changing role of case law and Repercussion General admission to the extraordinary appeal. However, we have to verify procedural utility that has been given to this important method of streamlining the work of the Supreme Court for, comparing to official figures, assess their actual effectiveness. In this aspect, the object of analysis was General Rebound, whose result, despite the theoretical efforts, exposes the ( still ) limited use of the filter and misleading presentation of the data that justify publicly.

Keywords: Filters CONTAINMENT. General REPERCUSSION. Role OF JURISPRUdENCE.

Sumário: Introdução. 1. Crise do Supremo Tribunal Federal. 2. Convite à litigiosidade e reserva de jurisdição. 3. Tribunal de Superposição; Corte Constitucional; político e jurídico. 4. O STF, o recurso extraordinário e as funções da Corte Constitucional. 5. Valorização da jurisprudência. 6. Repercussão geral. Conclusão. Referências.

\section{INTRODUÇ̃̃̃O}

A adoção de filtros e mecanismos de contenção para os Tribunais Superiores localiza-se no contexto social da chamada crise do Judiciário e, em um recorte menor, na crise dos Tribunais de Cúpula, com particular atenção para a sobrecarga 
do Supremo Tribunal Federal (STF).

O percurso aqui escolhido partirá da análise dessas crises num contexto histórico amplo, utilizando-se dados quantitativos sobre a evolução de processos entrados no STF desde a década de 1940 até o ano de 2010, com o propósito de tentar compreender a necessidade de adoção de filtros de acesso (ou contenção) para os Tribunais Superiores.

A crescente evolução da litigiosidade será observada a partir do paradigma de convite à litigiosidade, observando-se qual o conceito de acesso à justiça aí implicado e qual o paradoxo que acomete o Estado Constitucional pelas expressões judicialização da política e politização da justiça

No mesmo sentido, as origens da jurisdição constitucional serão recuperadas, ainda que em linhas gerais, a fim de tentar se compreender a natureza de uma Corte Constitucional e sua relação com o "político", bem como observar a judicialização da política em relação direta com o ativismo jurídico.

O Recurso Extraordinário será visto por seu papel político de viabilizar a função institucional do STF enquanto Corte Constitucional e por sua outra função de revisor de julgados associada à evidente finalidade pública que exerce.

A valorização da jurisprudência será analisada para compreender a necessidade e a crescente racionalização dos trabalhos do STF, extraindo-se um método de trabalho que simplifique e oriente o Poder Judiciário. Neste território, surge com força a figura do chamado precedente, que desempenha dupla coerência no sistema de justiça mas que, porém, não tem sistematizado seu método de reconhecimento, nem, pode-se dizer, previsão legal para sua escorreita aplicação.

Por fim, tratar-se-á da Repercussão Geral, um novo pressuposto de admissibilidade ao recurso extraordinário, enquanto filtro político que assegura e reforça a função nomofilática do STF. Ante os números apresentados pelo próprio Supremo Tribunal, verificar-se-á se a repercussão geral foi incorporada ao sistema de justiça enquanto um efetivo filtro de ordem constitucional e quais os limites que apresenta em sua aplicação, bem como quais os possíveis equívocos que gerariam uma falsa justificativa para legitimação do filtro.

\section{Crise do Supremo Tribunal Federal}

Observar a crise do Supremo Tribunal Federal diante do volume de recursos que inviabiliza o pleno exercício de suas funções de Corte de Superposição ${ }^{79}$, significa observar, com estreitamento de objeto, a crise da justiça brasileira. Os contornos desta permitem-nos compreender as feições e causas daquela.

${ }^{79}$ COUTO, Mônica Bonetti. O papel dos tribunais de cúpula, a missão do STF e a repercussão geral. In: De LUCCA Newton; MEYER-PFLUG, Samantha Ribeiro. Direito Constitucional Contemporâneo - Homenagem ao Professor Michel Temer. São Paulo: Quartir Latin, 2012, p. 744. 
O paradoxo da justiça brasileira talvez seja o ponto de partida para investigação aqui proposta, e a um só tempo, uma síntese da crise que historicamente o sistema de justiça enfrenta: "o amplo e efetivo acesso à justiça é um objeto promovido e perseguido por um Estado que não tem condições de suportá-lo"; e acresça-se, ainda, que:

a legislação processual, madura e sofisticada, parece não proporcionar, sozinha, o ideal de acesso efetivo à justiça. As características da sociedade contemporânea favorecem o aumento do volume e complexidade das demandas judiciais e o Estado, de seu turno, não dispõe de estrutura judiciária adequada para dar vazão ao número crescente de litígios. Com mais demandas e menos estrutura judicial, a chamada "crise da justiça” tende a aumentar $^{80}$.

No percurso da sociedade brasileira, a transformação estrutural de um país predominantemente agrário e rural para industrial e urbano (tomando como base 1930); a vivência do período do regime militar com restrito e contido acesso à justiça; e o posterior momento de abertura democrática com o novo paradigma da Constituinte de 1988 que alçou o Poder Judiciário ao centro da vida pública, são elementos sociológicos e jurídicos que podem ser apontados como determinantes para a crise da justiça e, portanto, para a crise do STF. São dados que, por si sós, justificam e explicam a multiplicação dos conflitos que fizeram crescer exponencialmente o volume de processos entrados no Poder Judiciário e, via de conseqüência, dirigidos ao $\mathrm{STF}^{81}$.

Concomitante às mudanças sociais, "as sucessivas constituições brasileiras ampliaram, gradativamente, a competência de julgamento do STF" 82 , ampliando o Controle Jurisdicional de Constitucionalidade até o atual formato de atribuições e competências outorgado na Constituinte de 1988, mas que, porém, não se esgotou diante das alterações introduzidas com a Emenda Constitucional 45/2004 - por intermédio da adoção de filtros de contenção para os Tribunais Superiores, como o recurso extraordinário e a súmula vinculante, e que refletem e produzem novas interpretações sobre o controle de constitucionalidade e os seus efeitos.

Neste amplo cenário da chamada crise da justiça brasileira, a problemática que se coloca ao STF não se resume à altíssima quantidade de recursos entrados e 80 SILVA, Paulo Eduardo Alves da. Gerenciamento de processos judiciais: desformaliza-
ção dos meios de solução de conflitos e gestão da burocracia judicial. 154f. Dissertação de
Doutorado em Direito - Faculdade de Direito do Largo São Francisco, Universidade de São
Paulo, 2009, p.10.
${ }^{81}$ SADEK, Maria Tereza. Judiciário: Mudanças e Reformas. São Paulo. Estudos Avançados,
Universidade de São Paulo, v. 18, n. 51, maio/agosto, 2004, pp.81;86.
${ }^{82}$ OLIVEIRA, Guilherme José Brás. Repercussão Geral das Questões Constitucionais e suas
conseqüências para o julgamento do recurso extraordinário. Dissertação de Mestrado em Di-
reito - Faculdade de Direito do Largo São Francisco, Universidade de São Paulo, 2009, p.30. 
pendentes de julgamento, a aumentar-lhe a taxa de congestionamento ${ }^{83}$, mas, em realidade, desdobra-se em uma limitadora problemática institucional e qualitativa que compromete as principais funções da Corte, inclusive indagando-lhe sobre o seu status verdadeiro de Corte.

Isso porque, como uma das autoras deste ensaio já registrou em outra oportunidade, tal situação afeta a função institucional maior do STF, que é a de zelar pela supremacia da Constituição ${ }^{84}$. Mas não apenas. O sufoco imposto pela quantidade de processos se traduz na "perda da importância dos julgados da mais alta Corte do país" $" 85$ e o enfraquecimento do seu poder ${ }^{86}$ enquanto tal.

E, embora a Constituição de 88 tenha universalizado o acesso ao Poder Judiciário ${ }^{87}$, é certo que o crescente aumento no volume de processos deu lugar aos chamados julgamentos de escala, em que as questões são analisadas em bloco ${ }^{88}$, sem maior análise dos temas. E aqui se consuma a perda de importância e o enfraquecimento dos julgados e do poder do STF, que acaba por sucumbir à necessidade de dar resposta à sociedade e ao seu próprio sistema sem a necessária observância da qualidade substantiva da prestação jurisdicional, desconsiderando a alta complexidade das causas que necessitam e consomem tempos de julgamentos ${ }^{89}$.

É justo lembrar, então, que o tempo do direito não é o tempo cotidiano, mas o tempo diferenciado e instituído para acolher o conflito no processo, sendo incompatível com o reinado da urgência das sociedades contemporâneas ${ }^{90}$.

\footnotetext{
${ }^{83}$ Indicador que pretende medir se a Justiça consegue decidir com presteza as demandas da sociedade, ou seja, se as novas demandas e os casos pendentes de períodos anteriores são finalizados ao longo do ano. CONSELHO NACIONAL DE JUSTIÇA. Justiça em Números 2009: Panorama do Judiciário Brasileiro. Brasília, 2010, pp.16;178

${ }^{84}$ COUTO, Mônica Bonetti. Op.cit. p. 752.

${ }^{85}$ Ibidem.

${ }^{86}$ OLIVEIRA, Guilherme José Brás. Op.cit.p.32.

${ }^{87}$ Quanto a este ponto, oportuno abrir-se um parêntese apenas para elucidar que, a nosso ver, inteira razão assiste a Rodolfo de Camargo Mancuso, quando assevera ser ufanista - e algo mentirosa, acrescentaríamos nós - a ideia de que o acesso à justiça (entendido na sua visão stricto sensu, é dizer, enquanto sinônimo de acesso ao Poder Judiciário) no Brasil é absoluto. Diz referido professor: "O inc. XXXV do art. 5 da vigente $\mathrm{CF} / 1988$, dispondo que a lei não pode subtrair à apreciação judicial históricos de lesão sofrida ou temida, tem merecido, ao longo do tempo, uma leitura que a descolou da realidade judiciária contemporânea, tomando ares tão ufanistas como irrealistas. " (Acesso à Justiça: condicionantes legítimas e ilegítimas. São Paulo: RT, 2011, p. 194).

${ }^{88}$ Ibidem, p.31.

89 Ibidem, p.31.

${ }^{90}$ Cf. SESSA, Márcio de. A Morosidade e o Gerenciamento de Processos Cíveis: da crise à instituição da razoabilidade no sistema de justiça. in Revista Eletrônica de Direito Processual da Universidade estadual do Rio de Janeiro. REDP, http://redp.com.br/arquivos/redp_8a_edicao.pdf, ano 5, vol. VIII, julho/dez. 2011, p. 741.
} 
O histórico da quantidade de processos distribuídos ao STF revela o potencial da saturação em afetar as funções institucionais, e essenciais, da Corte de Superposição, apresentando um cenário absolutamente incompatível com sua função de intérprete final da Constituição ${ }^{91}$.

Movimento processual do STF desde a década de $1940^{92-93}$

\begin{tabular}{|c|c|c|c|c|}
\hline Movimentação & Processos & Processos & Julgamentos & Acórdãos \\
\hline STF & Protocolados & Distribuídos & & Publicados \\
\hline 2013* & 8.016 & 4.965 & 9.875 & 1.338 \\
\hline 2012 & 66.930 & 43.190 & 80.730 & 10.702 \\
\hline 2011 & 59.581 & 35.476 & 90.607 & 14.103 \\
\hline 2010 & 71.670 & 41.014 & 103.869 & 10.814 \\
\hline 2009 & 84.369 & 42.729 & 95.524 & 17.704 \\
\hline 2008 & 100.781 & 66.873 & 130.747 & 19.377 \\
\hline 2007 & 119.324 & 112.938 & 159.522 & 22.257 \\
\hline 2006 & 127.535 & 116.216 & 110.284 & 11.421 \\
\hline 2005 & 95.212 & 79.577 & 103.700 & 14.173 \\
\hline 2004 & 83.667 & 69.171 & 101.690 & 10.674 \\
\hline 2003 & 87.186 & 109.965 & 107.867 & 10.840 \\
\hline 2002 & 160.453 & 87.313 & 83.097 & 11.685 \\
\hline 2001 & 110.771 & 89.574 & 109.692 & 11.407 \\
\hline 2000 & 105.307 & 90.839 & 86.138 & 10.770 \\
\hline 1999 & 68.369 & 54.437 & 56.307 & 16.117 \\
\hline 1998 & 52.636 & 50.273 & 51.307 & 13.954 \\
\hline 1997 & 36.490 & 34.289 & 39.944 & 14.661 \\
\hline 1996 & 28.134 & 23.883 & 30.829 & 9.811 \\
\hline 1995 & 27.743 & 25.385 & 34.125 & 19.507 \\
\hline 1994 & 24.295 & 25.868 & 28.221 & 7.800 \\
\hline 1993 & 24.377 & 23.525 & 21.737 & 4.538 \\
\hline 1992 & 27.447 & 26.325 & 18.236 & 2.482 \\
\hline
\end{tabular}

${ }^{91}$ COUTO, Mônica Bonetti. Op.cit. p.752.

${ }_{92}$ A tabela apresentada foi fracionada em décadas, porém, manteve a integridade a partir de 1987 em virtude da Constituição promulgada em 1988 para acompanhar o movimento da redemocratização e, posteriormente, para compreensão dos efeitos dos filtros de contenção; em especial, a partir da Lei 11.418/2006, que regulamentou a repercussão geral para o recurso extraordinário.

${ }_{93}$ BRASIL. Supremo Tribunal Federal. In http://www.stf.jus.br/portal/cms/verTexto.asp?servico $=$ estatistica\&pagina $=$ movimentoProcessual. Acessado em 07.03.2013. 


\begin{tabular}{|l|l|l|l|l|}
\hline 1991 & 18.438 & 17.567 & 14.366 & 1.514 \\
\hline 1990 & 18.564 & 16.226 & 16.449 & 1.067 \\
\hline 1989 & 14.721 & 6.622 & 17.432 & 1.886 \\
\hline 1988 & 21.328 & 18.674 & 16.313 & 4.760 \\
\hline 1987 & 20.430 & 18.788 & 20.122 & 4.876 \\
\hline 1980 & 9.555 & 9.308 & 9.007 & 3.366 \\
\hline 1970 & 6.367 & 6.716 & 6.486 & 3.328 \\
\hline 1960 & 6.504 & 5.946 & 5.747 & 4.422 \\
\hline 1950 & 3.091 & 2.938 & 3.371 & 3.395 \\
\hline 1940 & 2.419 & 2.211 & 1.807 & 1.469 \\
\hline Total $^{1}$ & 2.000 .596 & 1.673 .450 & 2.079 .613 & 475.809 \\
\hline
\end{tabular}

Neste contexto, apenas como exemplo do que será exposto adiante, um dado se mostra extremamente interessante: no período de 1990 a 2007, 1.215.948 processos foram recebidos no STF; 162.577 não foram distribuídos aos ministros e; no entanto, somente 98.405 processos, aproximadamente de $08 \%$, abordaram matéria constitucional. Não é possível que uma Corte de Superposição, com finalidade precípua de guarda e último intérprete da Constituição, seja acometida por um desvirtuamento crônico e sistêmico.

Com este cenário, a necessidade de se criar e adotar filtros e mecanismos de contenção para os Tribunais Superiores torna-se indispensável a fim de viabilizar o funcionamento e o desempenho do STF, enquanto Corte efetivamente Constitucional, e do próprio sistema de justiça que sofre diretamente com a instituição de $3^{\mathrm{a}}$ e $4^{\mathrm{a}}$ instâncias de julgamento. E, além do prejuízo institucional e social, há que se considerar, sobretudo, o prejuízo dos cidadãos-jurisdicionados.

\section{Convite À LITIGIOSIDAdE E RESERVA DE JURISDIÇÃo}

A garantia constitucional do acesso à Justiça tem recebido um tratamento exacerbado na medida em que se transformou num "convite à litigiosidade", o que causa, na visão de Mancuso, três efeitos deletérios: 1) a judicialização do conflito se torna o caminho natural e necessário, favorecendo e reforçando esta visão para o jurisdicionado; 2) a falsa idéia que toda pretensão resistida ou insatisfeita deva ser resolvida pela coisa julgada, com julgamento de mérito; 3) o desestímulo da busca pela solução alternativa dos conflitos, que sofre com a relutância da população acostumada a liturgia da justiça togada. ${ }^{94}$

${ }^{94}$ MANCUSO, Rodolfo de Camargo. A realidade judiciária brasileira e os Tribunais da Federação - STF e STJ: inevitabilidade de elementos de contenção dos recursos a eles dirigidos. In Processo e Constituição: estudos em homenagem ao Professor José Carlos Barbosa Moreira. Coordenação Luiz Fux [et. al]. São Paulo, RT, 2006, p. 1070. 
Estes efeitos são expressões da própria redução da concepção de Justiça que se cultua com o ritual da judicialização dos conflitos, transformando em sinônimo Justiça e Poder Judiciário.

Falseia-se ao cidadão comum uma esperança de singularidade no seu julgamento, favorecendo a crença que o seu caso é absolutamente diferente dos demais; esta expectativa, no entanto, o Estado brasileiro já demonstrou não ter condições de suportar e nem mesmo de responder satisfatoriamente unicamente pela via judicial. ${ }^{95}$

Para Mancuso, o que está realmente garantido no art. 5 XXXV, da CF, é uma cláusula de reserva para o Poder Judiciário; reserva de jurisdição, segundo Cândido Rangel Dinamarco. Alguns autores, como Mônica Sifuentes, afirmam que esta cláusula de reserva seria, mesmo com um pouco de exagero, "o novo nome da separação dos Poderes" "96, pela perspectiva da unidade do Poder e da sua funcionalização. $\mathrm{O}$ acesso à justiça é tão somente um dos meios pelos quais um conflito possa ser resolvido ${ }^{97}$. Há que se ampliar [e diferenciar] a concepção de justiça, de acesso à justiça e de efetividade.

Contudo, há que se receber essa interpretação sobre a reserva de jurisdição com cautela: o argumento é sedutor, porém, se entender que a abstração da separação de poderes possa ser reduzida a uma cláusula constitucional de reserva de jurisdição, legitima-se, no mesmo viés, a tendência de os Poderes Legislativo, Executivo e Judiciário imiscuírem-se reciprocamente e a partir da desigualdade de posições constitucionalmente previstas.

E nesta redução da concepção de Justiça à institucionalidade do Poder Judiciário cria-se um paradoxo: ao mesmo tempo em que se reduz a Justiça ao Judiciário, o poder do Poder Judiciário amplia-se superpostamente aos demais poderes do Estado.

O fortalecimento do Judiciário na destinação dos rumos da vida pública, e que causou o que se convencionou denominar de judicialização da política, constituiu uma força política que arrasta consigo a ratificação de toda justiça material e efetiva da vida social, desde pequenos conflitos até, em última instância, toda decisão nacionalmente importante. E a judicialização da política se revela, dialeticamente, no que se denominou de ativismo judiciário. Em outras palavras, tem-se a politização da justiça. ${ }^{98}$

\footnotetext{
${ }^{95}$ Ibidem.

${ }^{96}$ MANCUSO, Rodolfo de Camargo. Op.cit, apud SIFUENTES, Mônica. Súmula Vinculante - um estudo sobre o poder normativo dos tribunais. São Paulo, Saraiva, 2005, p.88.

${ }_{97}$ MANCUSO, Rodolfo de Camargo. Op.cit, p. 1071.

${ }^{98}$ Cf. entrevista de José Sarney, quando então presidente do Senado Federal, comentou sobre a judicialização da política: "Levamos ao extremo... Quando se perde qualquer coisa, dizse 'vou ao Supremo'. Isso implica em outro perigo, o da politização da Justiça"; in http:// br.reuters.com/article/topNews/idBRSPE90N07J20130124?pageNumber=2\&virtualBrandChannel $=0 \& s p=$ true. Acessado em 07.03.2013.
} 
Tem-se isso ao observar que toda justiça material e efetiva dependa, quase que obrigatoriamente, de passar pela via institucional do Poder Judiciário, mitigando o poder dos demais Poderes Legislativo e Executivo de exercerem-na diretamente, com autonomia e sem subordinação.

O Poder Judiciário, por sua Corte máxima, tem a vantagem deliberada de se alçar ao patamar de constituinte permanente na guarda e interpretação da Constituição. $\mathrm{O}$ entendimento sobre uma cláusula de reserva de jurisdição [que mitiga a separação dos poderes] autoriza e ratifica ao STF, juris et de jure, uma Superposição no Estado Constitucional em relação aos demais poderes.

Todo este cenário, independente da controvérsia que se estabeleça, afeta e influencia diretamente a litigiosidade crescente na via judiciária, latu sensu, e na saturação de litígios levados ao STF, strictu sensu.

Daí a necessidade de se pensar na Justiça para além da via institucional da judicialização, elaborando-se as vertentes de uma possível desjudicialização ${ }^{99}$ dos conflitos.

\section{Tribunal de Superposição; Corte Constitucional; político e Jurídico}

O movimento que instaura a criação de Cortes Constitucionais na Europa se inicia ao final da $2^{\mathrm{a}}$ Guerra Mundial com o intuito de conter, via Poder Judiciário, os horrores perpetrados com a ação direta e predominante dos outros Poderes durante a guerra. Ainda num contexto de prevalência do modelo francês em que o Poder Legislativo tinha preponderância sobre o Poder Judiciário enquanto defensor da Constituição, não podendo este se pronunciar sobre a constitucionalidade dos atos dos outros Poderes, a Constituição Austríaca foi a pioneira exceção a instituir uma jurisdição constitucional com poder de controle concentrado de constitucionalidade $^{100}$.

A barbárie da segunda Guerra Mundial tornou imprescindível a criação de mecanismos que contivessem os abusos governamentais. No plano internacional foram adotadas as Declarações e Convenções que criaram órgãos jurisdicionais com a atribuição de julgar as violações aos Direitos Humanos perpetrados pelos Estados. Em nível nacional, alguns Estados (Áustria, Itália e Alemanha) estabeleceram novas Constituições com jurisdição para o controle concentrado de constitucionalidade, "com la manifesta intención de detener los eventuales desbordes de los otros poderes del Estado que pudieram afectar los derechos fundamentales consagrados em esas Constituiciones", como garantias concretas, e não meras declarações, capazes

\footnotetext{
${ }^{99}$ Desjudicialização é o tema abordado na disciplina "Jurisdição: entre a segurança jurídica e a efetividade", ministrado pela Professora Doutora Mônica Bonetti Couto no âmbito do curso de Mestrado da Universidade Nove de Julho.

${ }^{100}$ OTEIZA, Eduardo. La Corte Suprema: entre la justicia sin política y la política sin justiça. La Plata: Liberia Editora Platense, 1994, pp.16-17.
} 
de ser tuteladas por um Tribunal com competência e poder suficiente para limitar as possíveis violações ${ }^{101}$.

Na história dos Estados Unidos da América o caso Marbury vs Madison foi o julgado paradigma que reconheceu à Corte Constitucional o poder de controle de constitucionalidade. Para Oteiza, trata-se do caso fundante da capacidade do Poder Judiciário declarar a inconstitucionalidade dos atos dos outros Poderes e que caracteriza a transcendência politica de sua Corte ${ }^{102}$.

A própria origem das Cortes Constitucionais, portanto, tem de uma decisão política em sua gênese e um processo político próprio de escolha de seus representantes habilitados a exercer o poder. Contudo, o elemento político, além de constitutivo em sua forma, também se encontra presente em sua atuação.

As Cortes Constitucionais são essencialmente políticas, desde que lhes sejam o viés jurídico inexorável; e são as Cortes Constitucionais essencialmente jurídicas, desde que lhes sejam o caráter político inexorável. A relação entre a política e o jurídico é constitutiva para as Cortes e exatamente o que as caracteriza como Cortes Constitucionais com poder de controle de constitucionalidade ${ }^{103}$. Para Eduardo Oteiza, a adoção deste modelo, Cortes com forte conteúdo político, significa o reconhecimento da falibilidade do legislador ${ }^{104}$.

Ademais, substancialmente as Cortes Constitucionais desempenham uma função política. O próprio ato de interpretar uma norma constitucional para lhe conferir determinando entendimento, como intérprete último da Constituição, faz com que os juízes participem do processo político ${ }^{105}$. Uma interpretação em detrimento de outra sempre é uma escolha política balizada pelo jurídico. Foi este o sentido quando Oteiza afirmou que:

La Corte no decide sus casos como meras abstracciones, la voluntad del juez se ve influenciada por los distintos efectos que podría producir según ella sea dictada en uno u outro sentido. Los jueces, al determinar cuál es la lectura que se le debe dar a una norma constitucional y fijar si se antepone uma norma individual o general, paticipan en el processo político.

E aqui nesse poder de interpretação fundado em escolhas político-jurídicas para aplicação da norma a determinado caso concreto, sob a consideração das circunstâncias históricas, inclusive, há que se vislumbrar o ativismo judicial.

No Brasil, como acima explicitado, a Constituinte de 88 foi o marco maior de constitucionalização do Estado com a definição, num caminhada histórica, de

\footnotetext{
101 Ibidem, p.31.

102 Ibidem, pp.16-17.

${ }^{103}$ Ibidem, passim.

104 Ibidem, p.31.

${ }^{105}$ Ibidem, p.27.
} 
ampliação do controle jurisdicional de constitucionalidade, passando a priorizar, ou no mínimo equilibrar, o controle concentrado com o controle difuso de constitucionalidade, até então predominante.

Do mesmo modo, a forma da escolha dos juízes ratifica o elemento político de sua constituição, sendo indicação da Presidência da República com necessária submissão à sabatina do Congresso Nacional.

Mais recentemente, com a Emenda 45/2004 o controle difuso, com a instituição do filtro da repercussão geral para o recurso extraordinário, ganhou sua caracterização de interesse público e de transcendência aos interesses privados das partes no caso concreto, aproximando os efeitos da declaração de constitucionalidade aos efeitos do controle concentrado, como se verá adiante. Trata-se de questão que reforça e consolida o papel eminentemente público da Corte Constitucional e, portanto, para além de jurídico, político.

Tem-se, portanto, com a constitucionalização do Estado brasileiro em 1988 e seus efeitos de judicialização da política e ativismo judicial, a caracterização da posição de Tribunal de Superposição do Supremo Tribunal Federal em relação ao Poderes Legislativo e Executivo na conformação político-jurídica de organização dos poderes do Estado.

\section{O STF, o Recurso extraordinário e as funções da Corte Constitucional}

Para viabilizar e reconduzir o STF ao "lugar de intérprete final da Constituição, velando por sua supremacia" ${ }^{106}$, faz-se necessário reconhecer a função pública que exerce na dupla feição de guarda da Constituição e revisor de julgados ${ }^{107}$.

Pelo controle concentrado o STF realiza sua precípua função de guarda da Constituição e, via controle difuso realizado pelo recurso extraordinário, opera como revisor de julgados de casos concretos em ato, no entanto, eminentemente político. Para Mônica Bonetti Couto, o recurso extraordinário possui inarredável interesse público, conseqüência de seu caráter político, sendo sua própria razão de ser ao consubstanciar mecanismo de manutenção da superioridade da Constituição. Tal caráter político e público ficou ainda mais evidente [e consolidado] com a adoção do requisito da repercussão geral para sua admissão ${ }^{108}$.

Cuida-se, portanto, de privilegiar a finalidade pública da Corte de Constitucional, transcendendo o mero interesse privado das partes no recurso extraordinário que instou o STF, via mecanismo eminentemente político e de interesse público, a julgamento de matéria constitucional.

\footnotetext{
${ }^{106}$ COUTO, Mônica Bonetti. Op.cit. 749.

${ }^{107}$ FUCK, Luciano Felício. O Supremo Tribunal Federal e a Repercussão Geral. São Paulo, Revista dos Tribunais; in Revista de Processo, v. 35, n. 181, março 2010, p.12.

${ }^{108}$ Ibidem, p.09
} 
Esta tendência de abstrativização ${ }^{109}$ do controle difuso tem na repercussão geral o amparo jurídico necessário para sua aproximação, no que tange aos efeitos da declaração, ao controle concentrado. Nota-se que ao controle concentrado a característica de controle abstrato esteve originaria e historicamente vinculada, dada sua formulação em tese; no entanto, a abstrativização do controle difuso com o reconhecimento da função política e pública do recurso extraordinário, porta aos efeitos da decisão de (in)constitucionalidade a característica de abstratação, transcendendo o interesse das partes para produzir maior eficácia à decisão, havendo de se conferir efeito erga omnes e (para se refletir) vinculante.

Neste sentido, uma das subscritoras deste trabalho já traduziu a tendência desta mudança de significação do recurso extraordinário, de transcendência de seu caráter subjetivo, de vínculo exclusivo às partes e, portanto, aos indivíduos, para reconhecer a sua força política e social em julgados do STF:

De fato, é perceptível uma tendência à abstrativização do controle difuso, o que é perceptível de alguns julgados mais recentes do Supremo Tribunal Federal. Julgamento que se pode dizer 'emblemático' foi o havido no Recurso Extraordinário 197.917/SP, em torno da fixação do número de vereadores em cada município, à luz do princípio da proporcionalidade (art. 29, IV, da CF). Tratava-se, como se disse, de um recurso extraordinário (e, portanto, de uma manifestação do Supremo Tribunal no controle difuso), mas, em relação a este julgamento, foi atribuída uma eficácia erga omnes (relator Min. Maurício Correa). Merece ser referida também a decisão tomada pelo Plenário do STF, no Habeas Corpus n. 82.959, originário de São Paulo (em 23.02.2006), relativamente à discussão da argüida inconstitucionalidade do $\S 1^{\circ}$, art. $2^{\circ}$, da Lei 8.072/90 (dispositivo este que veda a progressão de regime nos crimes hediondos $)^{110}$.

Esta tendência de abstrativização do controle difuso através da força do recurso extraordinário deve ser localizada, antes, em sua gênese: o pacto federativo do Estado brasileiro, com a repartição das competências legislativas no texto constitucional e com relação de autonomia entre os entes federados (União, Estados, Distrito Federal e Municípios), sem subordinação, portanto, propicia um cenário de pluralidade de fontes normativas. ${ }^{111}$

Neste contexto plural, de autonomia dos entes e de repartição de competências legislativas e observada a supremacia da Constituição, o recurso extraor-

\footnotetext{
${ }^{109}$ V. a respeito: COUTO, Mônica Bonetti. Objetivação do Recurso Extraordinário: notável tendência? São Paulo, Revista Dialética de Direito Processual, p.05.

${ }^{110}$ Ibidem, p.11, nota de rodapé 11.

${ }^{111}$ COUTO, Mônica Bonetti. O papel dos tribunais de cúpula, a missão do STF e a repercussão geral. 2010, pp. 745-746.
} 
dinário, fundado na controvérsia do caso concreto e amparado por sua previsão constitucional (art. 102, III, CF), exerce a função de manutenção da "integridade da ordem política" 112 do Estado brasileiro ao manter, por sua finalidade, a "inteireza do direito" 113 , a orientação futura para os julgados sobre o "conteúdo e alcance dos direitos" 114 , enquanto paradigma, e o modelo transcendente de questões privadas para públicas, com força normativa e orientadora para os demais órgãos do Estado e da sociedade ${ }^{115}$.

Portanto, da necessária manutenção da inteireza do Direito diante do pacto federativo, com o reconhecimento do "interesse público imanente ao recurso extraordinário e, mais proximamente, de sua missão de assegurar o respeito e a superioridade da Constituição, desponta a sua função nomofilática" ${ }^{116}$

Neste sentido que, para Eduardo Oteiza, "as Cortes são peças-chave na construção do Estado de Direito" e toca-lhes dar a leitura final da legislação, essa tarefa essencial aos sistemas jurídicos e que evidencia a dimensão pública de transcendência ao interesse das partes do caso concreto ${ }^{117}$. O equilíbrio entre as finalidades públicas e privadas possibilita que as Cortes mantenham e exerçam a capacidade de chegar "a interpretações que consolidem e ofereçam consistência ao sistema". ${ }^{118}$

Neste exercício de construção do Estado de Direito, de manutenção da inteireza do direito e de interpretação final da Constituição, a adoção do filtro da repercussão geral como pressuposto de admissibilidade do recurso extraordinário, advém importante contribuição teórica e procedimental para a efetivação do caráter político e de finalidade pública do controle difuso, com a aproximação dos seus efeitos aos do controle concentrado, a consequente abstrativização. A repercussão geral é o filtro político de uma Corte Constitucional Política e que assim merece e deve ser reconhecida para que se fuja de armadilhas ilusórias da exclusiva "tecnicidade", ou juridicidade, da Corte.

No mesmo sentido, mas em outra perspectiva funcional da finalidade pública do recurso extraordinário, há que se reconhecer a sua função paradigmática, ou modelar, que adverte à Corte Constitucional sobre seu papel orientador sobre o conteúdo e o alcance de direito, como afirma Oteiza. Trata-se de reconhecer ao STF a racionalidade de eixo instituinte de juridicidade ao país e a ordem político-jurídica.

\footnotetext{
112 Ibidem, p.08;21. Processo, v. 35, n. 187, set/2010, p. 230.

115 COUTO, Mônica Bonetti. Op.cit, p.750.

116 Ibidem, p.750.

${ }^{117}$ OTEIZA, Eduardo. Op.cit, pp. 226-227.

118 Op.cit, p.228.
}

${ }^{113}$ Cfe DANTAS, Bruno. Repercussão geral-Perspectivas histórica, dogmática e de direito comparado - questões processuais. São Paulo: Revista dos Tribunais, 2008.

114 OTEIZA, Eduardo. A função das Cortes Supremas na América Latina. História, paradigmas, modelos, contradições e perspectivas. São Paulo, Revista dos Tribunais; in Revista de 
Há que se assentar no presente as bases das decisões futuras sobre casos de mesma natureza jurídica.

A força normativa e a supremacia da Constituição, precípua missão, enquanto finalidade, e própria razão de ser, enquanto Poder, deve, ao transcender o caso concreto, transcender a própria Corte no processo de julgamento e, sobretudo, depois de seu pronunciamento. Talvez se deva elaborar a função paradigmática em consonância com o processo aberto de interpretação da Constituição, proposto por Peter Haberle ${ }^{119}$, como democratização do processo de interpretação. A hipótese colocada seria de, num processo democratizado e participativo de interpretação constitucional, a consolidação e o apoderamento das decisões da Corte, pela sociedade, se daria enquanto um eixo instituinte de juridicidade.

Essa possibilidade, e que efetivamente já ocorre no STF, vide as audiências públicas sobre os mais variados temas, tem adequação com o controle concentrado de constitucionalidade. A questão seria como adequar a pluralidade de interpretes participantes de um processo aberto de interpretação num caso concreto, via recurso extraordinário, no controle difuso.

\section{VALORIZAÇÃO DA JURISPRUDÊNCIA}

Nesta empreitada de valorização dos efeitos do controle difuso que o aproximou do controle concentrado, em evidente valorização da função política e constitucional da Corte Suprema, tem-se como pano de fundo o "crescimento do chamado direito judicial, (...) diagnosticado por Cândido Rangel Dinamarco, no que chamou de "caminhada de valorização da jurisprudência""120, que apresenta quatro passos: i) a súmula do STF, criada em 1963, fundada nos assentos da Casa de Suplicação, destinada a "favorecer a estabilidade da jurisprudência e, de igual modo, simplificar o julgamento das questões mais frequentes"121; para Victor Nunes Leal era um método de trabalho do Tribunal; ii) a chamada Lei dos Recursos, Lei 8038/1990, que trouxe para o plano legal o que era meramente regimental, ratificando os poderes do relator e dando igual tratamento ao recurso especial processado no STJ, instituído um ano antes, criado na Constituinte de 1988; iii) a Lei 9.756/1998 que "ampliou os poderes do relator, seja nos Tribunais locais ou nos de superposição (STJ e STF), sempre em associação com a observância dos precedentes judiciários"; iv) o "efeito vinculante

${ }^{119}$ HABERLE, Peter. Hermenêutica Constitucional: a sociedade aberta dos intérpretes da Constituição para a interpretação pluralista e "procedimental" da Constituição. Porto Alegre, 1997. Sergio Antonio Frabris Editor. Tradução Gilmar Mender.

${ }^{120}$ MANCUSO, Rodolfo de Camargo. A realidade judiciária brasileira e os Tribunais da Federação - STF e STJ: inevitabilidade de elementos de contenção dos recursos a eles dirigidos. In Processo e Constituição: estudos em homenagem ao Professor José Carlos Barbosa Moreira. Coordenação Luiz Fux [et. al]. São Paulo, RT, 2006, p. 1069.

${ }^{121}$ MANCUSO, Rodolfo de Camargo. Op.cit, p. 1069. 
das decisões do Plenário do STF no controle de constitucionalidade - quer difuso ou concentrado $^{122}$.

Mancuso acrescenta o quinto passo nesta caminhada de valorização da jurisprudência, advindo com a Emenda 45/2004, ao afirmar o prognóstico de Dinamarco sobre a "força dos precedentes com eficácia geral e efeito vinculante", a positivação da Súmula Vinculante projeta um inegável efeito preventivo geral, na medida em que desestimula a judicialização de pretensões contrárias aos seus enunciados. ${ }^{123}$

Além disso, nesta caminhada de valorização da jurisprudência, a abstrativização dos efeitos do controle difuso, aproximando-o do controle concentrado, também expressa outro movimento: a aproximação dos modelos jurídicos da commow law e da civil law.

A mudança (na Europa pós segunda guerra; nos Estados Unidos com o caso Marbury vs Madison; e no Brasil com a constituinte de 1988) que deslocou o Estado Legislativo, cujo eixo central eram os códigos, para o Estado Constitucional, cuja ênfase reside na jurisdição e a partir da separação entre texto e norma, provocou, consequentemente, alterações e diferenças na interpretação jurídica de cada contexto histórico.

No Estado Constitucional, as normas são "fruto de uma outorga de sentido aos textos pelos seus destinatários". Até então, no Estado Legislativo, concebia-se o texto e a norma enquanto unidade e sinônimo, "sendo função da jurisdição tão somente declarar a norma preexistente para solução do caso concreto". ${ }^{124}$

Foram, portanto, três grandes mudanças ocasionadas por essa passagem histórica do Estado Legislativo ao Estado Constitucional: a primeira no terreno das fontes jurídicas, com a convivência de uma pluralidade de fontes: o Código perde sua centralidade e plenitude para desempenhar a função de centralidade infraconstitucional, muitos e variados instrumentos concorrem para disciplinar a vida social, são estatutos, leis especiais, instrumentos infra-legais, etc; segundo, na compreensão da natureza da interpretação jurídica, como dito; e terceiro, com a técnica legislativa. Este deslocamento, aponta a doutrina, muda a vocação, de outrora, para a legislação e a ciência do Direito para a vocação, dos tempos atuais, para a jurisdição, ou, em última instância, para a vocação para o processo. ${ }^{125}$

Vocação para o processo, eis o cenário atual em que, no caso brasileiro, o STF exerce a Superposição de Corte constitucional e política. Isso, no contexto e no movimento histórico de valorização da jurisprudência, para Daniel Mitidiero, traduz-se, atualmente, na importância central que a decisão judicial apresenta:

\footnotetext{
${ }^{122}$ Ibidem, p.1069.

${ }^{123}$ Ibidem.

${ }^{124}$ MITIDIERO, Daniel. Fundamentação e Precedente - dois discursos a partir da decisão judicial. São Paulo, Editora Revista dos Tribunais, Revista de Processo - Repro, 206, 2012, p. 66.

${ }^{125}$ Ibidem, pp. 65-66.
} 
enquanto seja a garantia de contraditório para as partes do caso concreto, extrai-se desta decisão os fundamentos que podem ser elevados à categoria de ratio decidendi, aplicável, portanto, suas razões generalizáveis e abstratas, na resolução de outros casos concretos, conferindo confiabilidade e segurança para o sistema de justiça e para os jurisdicionados. ${ }^{126}$

Trata-se da dupla coerência da decisão judicial: congruência social e consistência sistêmica. São dois discursos diferentes e com destinatários igualmente diferentes, como aponta Mitidiero, o discurso para o caso concreto "constitui direito fundamental da parte e compõe o núcleo duro do direito ao processo justo (arts. $5^{\circ}$, LIV, e 93, IX, da CF/1988)". O discurso do precedente é de "ordem institucional, está estruturado para desenvolver a unidade do direito e visa à realização da segurança jurídica, da igualdade e de coerência normativa" ${ }^{127}$

Percebe-se, portanto, que a função institucional preconizada pelo precedente enquanto garantia e consistência sistêmica, confiabilidade e segurança jurídica, vinculam-se ao desempenho da função nomofilática pela Corte Constitucional ao voltar-se para a manutenção da unidade do Direito. Contudo, como aponta Mitidiero, a partir da pesquisa sobre commom law que a doutrina deve buscar os meios pelos quais os precedentes possam ser corretamente identificados, aplicados em juízo a partir da adoção de um sistema de precedentes criticamente elaborado. ${ }^{128}$

Tal como se apresenta hoje, a caminhada de valorização da jurisprudência que resultou na adoção objetiva de filtros de contenção para os Tribunais Superiores, como a súmula vinculante e a repercussão geral, carece de previsão legal que regulamente um sistema de precedentes e reconheça, primeiro, a existência dos precedentes e, a partir disso, qual o método de extração e construção do discurso da ratio decidendi que gere sua validade e seus efeitos jurídicos no sistema de justiça. ${ }^{129}$

Portanto, por um lado, têm-se avanços significativos na evolução do controle de constitucionalidade quanto à tendência de os efeitos de abstração erga omnes e vinculante emanarem também pela via difusa; por outro, há que se reconhecer que mesmo esta tendência ainda prescinde de regulamentação, não sendo claro quais decisões e por qual método será reconhecido o efeito nomofilático do recurso extraordinário.

Esta ausência de critérios objetivos quanto à escolha de julgados que terão o reconhecimento de sua abstrativização dialoga, potencialmente, com a adoção de

\footnotetext{
${ }^{126}$ Ibidem, passim.

127 Ibidem, pp. 62-73.

128 Ibidem, p.69.

${ }^{129}$ Neste sentido deve-se ter extrema cautela ao nominar de precedentes figuras existentes no direito brasileiro algo análogas ao precedente do direito anglo-saxão (v.g., jurisprudência dominante, súmula). Ver, por todos, a crítica muito bem construída por Lênio Streck e Georges Abboud, na obra "O que é Isto - O precedente Judicial e as súmulas Vinculantes”, Ed Livraria do Advogado, 2013 (2.edição).
} 
um sistema de precedentes que exerça a função nomofilática endereçada à consistência sistêmica da Justiça e do poder, enquanto eixo instituinte de juridicidade, do Supremo Tribunal Federal.

\section{REPERCUSSÃo GERAL}

A repercussão geral imprimiu nova feição ao recurso extraordinário, potencializou sua função política ao permitir a organização do discurso político-jurídico, fundado no precedente, para dirigir o Judiciário e a sociedade no tocante à segurança jurídica e confiabilidade na instituição.

Como visto, a razão de ser do recurso extraordinário deita raízes no sistema federativo adotado pelo Brasil, cuja forma de organização política do Estado implica na descentralização do poder estatal e na autonomia dos entes que a integram e, em específico, na repartição das competências normativas, o que implica diretamente na importância da função nomofilática do recurso extraordinário em manter a integridade do Direito brasileiro ${ }^{130}$, seja com endereçamento ao sistema de justiça, a sociedade e seja materialmente enquanto intérprete final da Constituição.

Portanto, a supremacia da Constituição constitui princípio dos mais importantes para o reconhecimento de uma estrutura escalonada no ordenamento jurídico e da sua própria rigidez. O recurso extraordinário, como instrumento de controle de constitucionalidade pela via difusa, detém especial importância no regime federalista, marcado pela pluralidade de fontes normativas e pela supremacia da Constituição. É necessário um recurso com as características que considerem essas peculiaridades. ${ }^{131}$

O recurso extraordinário, neste sentido, foi dotado de feição eminentemente política. Destarte, sirva aos interesses das partes, a razão de ser do recurso extraordinário comporta inarredável interesse público, ainda mais com a adoção da repercussão geral. Deste modo, ao mesmo tempo em que o STF é um tribunal político, é, também, colocado em grau recursal com a possibilidade da revisão da decisão anterior, a quo. Com a repercussão geral, sobreleva-se, portanto, as funções nomofilática e paradigmática do STF através do recurso extraordinário.

Tal como a Súmula Vinculante, a repercussão geral foi elaborada na esteira da valorização da jurisprudência, além do que, na realidade, não se trata de mecanismo inteiramente novo no ordenamento brasileiro. Luciano Felício Fuck relembra o instituto da argüição de relevância da questão federal. Com os poderes outorgados pela Constituição de 1967-1969, o STF passou a disciplinar o recurso extraordinário por seu regimento interno, mecanismo que utilizou para restringir paulatinamente $o$ seu cabimento. Através da Emenda Regimental no 3 de 1975, o STF limitou ainda

\footnotetext{
${ }^{130}$ COUTO, Mônica Bonetti. O papel dos tribunais de cúpula, a missão do STF e a repercussão geral. 2010, p.752.

131 Ibidem, p.04.
} 
mais as hipóteses de cabimento do recurso extraordinário com a criação da argüição de relevância da questão federal, depois consagrada pela Emenda Constitucional $\mathrm{n}^{\mathrm{o}}$ 7/1977. 132 "A argüição de relevância foi desenvolvida para filtrar o conhecimento do recurso extraordinário fora dos casos de alegação de ofensa a norma constitucional e das hipóteses destacadas no Regimento Interno do STF"133. Tratava-se, pois, de ato político de seleção das questões federais "por seus reflexos na ordem jurídica e considerados os aspectos morais, econômicos, políticos ou sociais da causa". ${ }^{134}$

Contudo, a argüição de relevância não obteve o êxito suficiente para se manter no ordenamento jurídico com a chegada da Constituição de 1988; o modelo da argüição de relevância "recebeu severas críticas por conta de sua falta de transparência e de legitimidade", além da carência de fundamentação de seus acórdãos ${ }^{135}$. Do mesmo modo, o baixíssimo percentual de acolhimento da argüição de relevância estimulou a oposição dos advogados ao instituto. ${ }^{136}$

Apesar disso, para Mancuso, a não recepção pela Constituição de 1988 do instituto da argüição de relevância de questão federal e de o poder faculdade concedido ao STF, pela Constituição de 1967-1969, de disciplinar o recurso extraordinário por seu Regimento Interno, indicando as "causas de que conheceria"137, franqueou o acesso desmesurado de recursos ao STF e ao recém criado STJ. ${ }^{138}$

Sem filtros e com o vertiginoso aumento da litigiosidade, a jurisprudência defensiva foi o mecanismo espontâneo adotado pelos ministros do STF para conter a enorme carga de processos. No entanto, a adoção desta autodefesa também causou o enfraquecimento da questão constitucional em favor de um processualismo exacerbado. É neste sentido que Luciano Felício Fuck apontou o cenário anterior à Emenda Constitucional 45/2004:

Como exposto, até a EC 45/2004, a excessiva sobrecarga de feitos no STF provocou o desenvolvimento de jurisprudência cada vez mais defensiva

\footnotetext{
${ }^{132}$ FUCK, Luciano Felício. O Supremo Tribunal Federal e a repercussão geral. In: WAMBIER, Teresa Arruda Alvim (Coord.). São Paulo, Revista dos Tribunais. Revista de Processo, ano 35, n.191, mar/2010, p.20.

${ }^{133}$ Ibidem, p.20.

${ }^{134}$ BRASIL. Supremo Tribunal Federal, Regimento Interno, art. 327, §1 ${ }^{\circ}$; redação da Emenda Regimental n. 2/1985.

${ }^{135}$ FUCK, Luciano Felício. Op.cit, p.21.

${ }^{136}$ MANCUSO, Rodolfo de Camargo. A realidade judiciária brasileira e os Tribunais da Federação - STF e STJ: inevitabilidade de elementos de contenção dos recursos a eles dirigidos. In Processo e Constituição: estudos em homenagem ao Professor José Carlos Barbosa Moreira. Coordenação Luiz Fux [et. al]. São Paulo, RT, 2006, p. 1076.

${ }^{137}$ BRASIL. Emenda Constitucional n. 1/1969, art. 119, III, redação da Emenda Constitucional n. 7/1977.

${ }^{138}$ MANCUSO, Rodolfo de Camargo. Op.cit. p.1075.
} 
no que tange ao conhecimento do recurso extraordinário. Como efeito, o caráter extraordinário do apelo extremo denotava-se cada vez mais pela excepcionalidade do conhecimento do recurso e cada vez menos como remédio constitucional apto a harmonizar a interpretação das normas constitucionais. A própria violação de normas constitucionais perdia importância em face de diversos requisitos processuais que deveriam ser preenchidos para que o recurso fosse conhecido (...). De certa forma, inverteu-se a hierarquia de propósitos: a aplicação e a harmonização da interpretação das disposições constitucionais subordinavam-se às normas e aos institutos de processo civil, que deixaram de ser mero instrumento para absorverem quase por completo a atividade do $\mathrm{STF}^{139}$.

Com a Emenda Constitucional 45/2004 inicia-se a fase de intensa e necessária racionalização dos trabalhos do STF para pacificação das controvérsias constitucionais perante si próprio e a todo Poder Judiciário. Além da Súmula Vinculante, foi instituída a repercussão geral enquanto um novo pressuposto de admissibilidade ao Recurso Extraordinário: não se trata de mera regra de direito processual, mas de instituto de jurisdição constitucional que propicia a aplicação eficaz e homogênea das normas constitucionais.

O que se repercute por força da transcendência é a "questão constitucional discutida" e não a causa, as partes ou o recurso extraordinário, propriamente. Cuidase de objetivação do controle difuso ${ }^{140}$; de critério político-jurídico que torna possível a abstrativização do controle difuso em direção ao efetivo exercício de Corte Constitucional e Política, tal como ocorre com o controle concentrado.

Portanto, somente quando se reconhecer a transcendência do caráter subjetivo do caso concreto, superando os interesses privados das partes, será admitido o recurso extraordinário. "Para efeito da repercussão geral, será considerada a existência, ou não, de questões relevantes do ponto de vista econômico, político, social ou jurídico, que ultrapassem os interesses subjetivos da causa" ${ }^{141}$. De outro modo, a repercussão geral permite obstar o recurso extraordinário ainda quando presentes os demais pressupostos de admissibilidade. ${ }^{142}$

Contudo, a despeito da importante função que a repercussão geral veio a cumprir para alçar o STF ao efetivo posto de Corte Constitucional no desempenho das funções nomofilática e paradigmática, há que se observar o uso que o STF fez nos últimos anos para elaborar algumas considerações. Segundo as informações oficiais através do portal on line do STF, conforme os dados específicos sobre a repercussão geral, têm-se o seguinte:

\footnotetext{
${ }^{139}$ FUCK, Luciano Felício. Op.cit, pp. 21-22.

${ }^{140}$ Ibidem, pp. 22-23.

${ }^{141}$ BRASIL, Código de Processo Civil, art. 543-A, §1º; incluído pela Lei 11.418/2006.

${ }^{142}$ MANCUSO, Rodolfo de Camargo. Op.cit, p. 1077.
} 
Dos 629 casos de repercussão geral apreciados entre o $2^{\circ}$ semestre de 2007 e o $2^{\circ}$ semestre de 2012 , cerca de 5 anos: 445 (70,75\%) temas com repercussão geral reconhecida; $7(1,11 \%)$ temas em análise; e $177(28,14)$ temas com repercussão negada. Dos casos com repercussão negada, 142 (80,23\%) referem-se a matéria infraconstitucional e apenas $35(19,77 \%)$ tiveram repercussão negada por outro motivo. ${ }^{143}$ Conforme tabela:

\begin{tabular}{|l|l|l|l|l|l|}
\hline & $\begin{array}{l}\text { Repercussão Ge- } \\
\text { ral reconhecida }\end{array}$ & \multicolumn{2}{|l|}{ Repercussão Geral negada } & Em análise & Total \\
\hline Quantidade & 445 & 177 & 07 & 629 \\
\hline Porcentagem & $70,75 \%$ & $28,14 \%$ & 35 & -- & $11 \%$ \\
\hline Quantidade & -- & 142 & -- & -- \\
\hline Tema & Constitucional & $\begin{array}{l}\text { Infraconsti- } \\
\text { tucional }\end{array}$ & $\begin{array}{l}\text { Outro } \\
\text { motivo }\end{array}$ & -- \\
\hline Porcentagem & -- & $80,23 \%$ & $19,77 \%$ & -- & - \\
\hline Período & Entre o $2^{\circ}$ semestre de 2007 e o $2^{\circ}$ semestre de 2012 & \\
\hline
\end{tabular}

As informações oficiais do STF, reproduzidas na tabela acima, revelam uma distorção no uso do filtro da repercussão geral: dos $28.14 \%$ dos casos com repercussão negada, mais de $80 \%$ deles se referiam a matéria infraconstitucional, sendo desnecessária a existência de um filtro com as características da repercussão geral para obstar tais recursos. Estes casos não superariam os demais pressupostos de admissibilidade do recurso extraordinário, sendo inócuo, portanto, imputá-los ao filtro político da transcendência sendo que não ofertavam violação à norma constitucional para serem apreciados pelo STF.

$\mathrm{Na}$ realidade, se reduzir do gráfico a quantidade de casos com matérias infraconstitucionais, tem-se que apenas $7,19 \%$ de recursos foram obstados de subir ao STF em virtude da repercussão geral. Ou seja, dos 487 casos apreciados no período supra, apenas 35 tiveram a repercussão geral negada em virtude de outros motivos que não a infraconstitucionalidade da matéria aventada.

Apesar de a repercussão geral ter sido instituída com o intuito de filtrar matérias que não transcendessem o interesse privado das partes, há o indicativo que sua função política e institucional não foi consolidada pelo STF.

Esta associação entre a não repercussão geral e as matérias infraconstitucionais foi também vislumbrada em pesquisa realizada pelo Ministério da Justiça, cuja constatação aponta para a negativa da existência de um filtro consolidado de relevância constitucional.

${ }^{143}$ BRASIL. Supremo Tribunal Federal. http://www.stf.jus.br/portal/cms/verTexto.asp?servico=jurisprudenciaRepercussaoGeral\&pagina=numeroRepercussao acesso em 10.03.2013. 
Nas decisões do STF tem havido forte associação entre ausência de repercussão geral e infraconstitucionalidade. O Tribunal vem tendendo a admitir como possuidora de repercussão geral a grande maioria dos casos em que a questão discutida é realmente de índole constitucional. Assim, neste momento não é o art. 543-A do Código de Processo Civil, mas o art. 543$\mathrm{B}$, o mais influente na sistemática da repercussão geral. $\mathrm{O}$ que se faz, na verdade, é aplicar este último artigo para os casos infraconstitucionais que não dariam ensejo a recurso extraordinário e, por isso, obviamente não estariam sujeitos ao filtro de relevância que foi estabelecido pelo art. 543-A. Assim, é reforçada a constatação, discutida acima, de que não há, no momento, propriamente um filtro consolidado de relevância constitucional.

Em outras palavras, há predominância do uso do critério da infraconstitucionalidade da questão para declarar a inexistência de repercussão geral, o que faz com que praticamente todas as questões que escapam desse crivo sejam consideradas constitucionais e dotadas de repercussão geral. Assim, a repercussão geral parece estar funcionando muito mais como um mecanismo de racionalização do sistema a partir do estabelecimento de quais questões não devem ser discutidas na Corte (e, portanto, não devem ser para lá remetidas) do que propriamente um filtro das questões constitucionais relevantes. ${ }^{144}$

São várias as razões que podem explicar a ineficácia da repercussão geral enquanto filtro de índole constitucional e política. Esta exploração foge aos limites deste ensaio, mas apenas por indicativo, pode-se apontar uma possibilidade de, numa primeira fase do instituto, o STF possa estar a demarcar sua fronteira constitucional, posto que anteriormente sua função de corte de revisão era predominante e "demarcando as fronteiras do que pode ser considerada uma controvérsia genuinamente constitucional" 145 . Somente em momento posterior, sem a pressão da sobrecarga recursal, talvez seja possível a consolidação do filtro político-jurídico enquanto Corte predominantemente Constitucional e Política.

Contudo, várias determinantes influem nesse processo, inclusive a cultura estabelecida no STF de, anteriormente ao filtro, toda e qualquer questão apresentar relevância constitucional. Isso nos limites de um paradigma de fragilidade institucional, sem o viés de interesse público que acompanha o recurso extraordinário e que exige a força política e pública para imposição da supremacia da norma constitucional.

\footnotetext{
${ }^{144}$ BRASIL, Ministério da Justiça. A Repercussão Geral e o Sistema Brasileiro de Precedentes. Série Pensando o Direito. SUNDFELD, Carlos Ari; SOUZA, Rodrigo Pagani (Coord), São Paulo, 2010, p.29.

145 Ibidem, p.29.
} 


\section{Conclusão}

Diante a crescente litigiosidade de nossa sociedade, sobretudo elevada com a redemocratização fundada numa Constituição que a si reserva a última palavra sobre a legalidade e a constitucionalidade dos atos estatais e dos atos da vida privada, cujo paradigma cultural traduz como sinônimos Justiça e Poder Judiciário, os filtros e mecanismos de contenção de processos aos Tribunais Superiores são necessários para a racionalização do trabalho, ofertando resposta quantitativa ao sistema de justiça e a sociedade, como para a efetiva elevação do STF ao patamar de Corte Constitucional e Política, em uma evidente resposta qualitativa e institucional ao sistema e a sociedade.

Há que se aprofundar essa visão ao perceber que ambas as respostas, ao fundo, direcionam-se aos jurisdicionados como garantia do contraditório, da segurança jurídica e da confiabilidade na instituição. O prazo razoável da duração processual deve ser compreendido enquanto eixo instituinte da temporalidade judicial, perpassando todo o sistema de justiça enquanto parte de sua racionalidade.

Por outro lado, há que ampliar a concepção de Justiça, extrapolando os limites institucionais versados no devido processo. A redução da Justiça ao Poder Judiciário criou um paradoxo: se toda justiça se reduz ao judiciário, o judiciário se amplia para decidir toda questão da vida social e política. O Estado Constitucional da constituinte de 88, desta forma, judicializou a política, alçando-se ao lugar de Superposição em relação aos demais Poderes. No entanto, ao mesmo movimento que se tem a judicialização da política, tem-se, ao mesmo modo de Superposição de intérprete da Constituição, a politização do judiciário. Toda interpretação da Constituição é política e, portanto, são escolhas de como se decidir um caso concreto.

Ambas as facetas de politização e judicialização são inerentes à concepção de Estado Constitucional fundado numa jurisdição constitucional de controle de constitucionalidade. Esta a razão da inexorável relação dialógica entre Corte, Política e Constituição. Este desenho atual, não sem razão, suscita questões sobre a própria conformação da Democracia. O Supremo, Corte Constitucional e Política, exercendo o poder de último intérprete da Constituição transforma-se, de fato, de direito e por direito, numa espécie de constituinte permanente.

Eis aqui a problemática: neste exercício de constituinte permanente, quem lhe conferiu legitimidade? Com poder conferido por quem? Parece, num juízo preliminar, que o papel de constituinte permanente não encontra amparo na legitimidade conferida em determinado espaço e tempo próprio aos legisladores constituintes em virtude de outorga popular. Este exercício não teria vínculos com a legitimidade originária e o poder conferido pela Constituição não abarcaria a interpretação para além dos limites objetivos da própria Constituição. Isso nos traria a problemática (muito bem aceita) de interpretações da Constituição que a modificam sem, contudo, a redução de seu texto. E uma outra série de questões, como por exemplo, a modulação 
dos efeitos das decisões sobre constitucionalidade.

Ainda, o alcance de Superposição da Corte Suprema pode ter causado, e assim parece, o esvaziamento político do Legislativo, reduzindo seu papel e ocorrendo uma perda de importância perante a sociedade. No mesmo sentido, pode-se observar a relação entre Executivo e Legislativo, marcada por uma aliança em nome da governabilidade, neste contexto da Superposição do Judiciário, talvez como uma união de forças para a execução da Política [escolhida].

E nesta superposição do STF, dentro do federalismo de múltiplas fontes legislativas, cumpre o Recurso Extraordinário o papel de manutenção da inteireza do Direito e da orientação e conformação do Poder Judiciário e sociedade às decisões da Corte Constitucional e Política. O instituto da Repercussão Geral enquanto filtro político dentro dos pressupostos de admissibilidade do Recurso Extraordinário reforça a finalidade pública deste recurso que necessita transcender aos interesses subjetivos das partes para justificar e legitimar o STF como o guarda da Constituição no desempenho da função de um eixo instituinte de juridicidade do sistema de justiça e para a sociedade. Quanto a isto, no que concerne aos jurisdicionados litigantes em processos, a contraditório efetivamente exercido dentro da cooperação e do debate dos fundamentos, a segurança jurídica e a confiabilidade na instituição, cumpre também função material o recurso extraordinário e a repercussão geral.

Neste percurso, a valorização da jurisprudência, caminha iniciada desde a Casa de Suplicação, com os assentos, e depois com a Súmula de Jurisprudência Predominante, por previsão regimental, por emenda constitucional, da Corte em 1963, muitos mecanismos de filtros foram instituídos e aprimorados. Neste trabalho se privilegiou, pela razão das funções institucionais de finalidade pública, a Súmula Vinculante, a repercussão geral e um possível sistema de precedentes a ser elaborado para o ordenamento brasileiro.

O sistema de precedentes se mostra uma interessante idéia, sobretudo pelo papel que o precedente pode desempenhar em consonância com a finalidade pública de manutenção da inteireza do direito, sua função nomofilática, com o discurso direcionado para o sistema de justiça, enquanto ordenamento e orientação, o que lhe acarreta função paradigmática também. Contudo, as questões que se colocam fazem frente aos mecanismos que já se possui. Qual a diferença entre um precedente e uma súmula? Entre um precedente e uma súmula vinculante? Qual o método de extração ou elaboração da ratio decidendi para servir de fundamento ao sistema jurídico? Qual a diferença entre o precedente e a decisão que conhece da repercussão geral de um recurso extraordinário? Ou que não conhece? O que há em comum e o que afasta esses mecanismos de um sistema de precedentes? Há muito o que se debater sobre o assunto, inclusive sobre as vicissitudes do sistema de justiça que impedem o exercício da regular função de súmulas e da repercussão geral.

A Súmula Vinculante, neste contexto da valorização da jurisprudência, incorpora-se ao ordenamento com a Emenda 45/2004, sendo notória a observação que 
sua primeira proposta ocorreu em 1994. Com a Reforma do Judiciário, a Súmula Vinculante surge com a força de imprimir poder político e jurídico às decisões do Supremo, vinculando o Poder Judiciário e a Administração Pública direta e indireta e prevendo sua própria fórmula de revisão e cancelamento. Notório, ainda, que os legitimados, além da própria Corte, a propor uma Súmula Vinculante, oriunda de casos concretos via controle difuso de constitucionalidade, são os mesmos legitimados ao exercício do controle concentrado de constitucionalidade.

A notável tendência, portanto, foi a abstrativização dos efeitos do controle difuso, aproximando-o do controle concentrado de constitucionalidade. A Emenda 45 apresenta-se como o principal marco de efetiva constituição, ao menos teórica, do STF em Corte Constitucional e Política. Tal foi assim que a Repercussão Geral, de caráter eminentemente político, reforçou a natureza pública do Recurso Extraordinário, fazendo com que a decisão, obrigatoriamente, tenha de transcender os limites subjetivos do caso concreto.

Contudo, desde sua efetiva regulamentação, pela Lei 2006, a repercussão geral não desempenhou o papel ao qual foi instituída e incumbida pela Reforma. A análise do números apresentados pelo STF de 2007 a 2012 revelam que sua utilização passou ao largo da função política e jurídica: a imensa maioria das decisões que negaram o conhecimento da Repercussão Geral o fizeram porque a matéria tratada no recurso era infraconstitucional. Portanto, matérias que independeriam do filtro da repercussão para não serem admitidos no STF. Por outro lado, a imensa maioria das matérias constitucionais tiveram seu reconhecimento de repercussão para seguir julgamento pelo STF.

Os números são alarmantes: apenas 7,19\% de recursos foram obstados de subir ao STF em virtude da repercussão geral de matéria constitucional e não os anunciados $28,14 \%$. Este número se revela com a exclusão da quantidade de processos com negativa de repercussão por serem matérias infraconstitucionais.

No entanto, este resultado deve ser contextualizado dentro da sobrecarga de processos entrados no STF, cuja redução vem ocorrendo nos últimos anos com a contribuição da repercussão geral, ainda que utilizada sem toda a força de sua atribuição. No mais, há se perguntar se não estamos diante um movimento de consolidação da Repercussão Geral que depende, inicialmente, de uma drástica redução de processos a serem julgados. Por outro lado, há se especular sobre a própria cultura da instituição que se acostumou a julgar a constitucionalidade de todo tipo e de importância de demandas, causando uma dificuldade inicial de se reconhecer os valores intrínsecos ao instituto novo e que depende de uma mudança de racionalidade também.

Pode-se vislumbrar que o cenário seja favorável há uma disputa dos significados da Repercussão Geral, instando, para além da juridicidade e politicidade do tema, a seara da cultura jurídica da Corte Suprema e do próprio sistema de justiça. 


\section{REFERÊNCIAS}

ARRUDA ALVIM, José Manoel de. A EC n. 45 e o instituto da repercussão geral. In: WAMBIER, Teresa Arruda Alvim et al. (Coord.). Reforma do Judiciário - Primeiras Reflexões sobre a Emenda Constitucional n ${ }^{\circ}$ 45/2004. São Paulo: Revista dos Tribunais, 2005, pp. 63-100.

BRASIL, Ministério da Justiça. A Repercussão Geral e o Sistema Brasileiro de Precedentes. Série Pensando o Direito. SUNDFELD, Carlos Ari; SOUZA, Rodrigo Pagani (Coord), São Paulo, 2010.

COUTO, Mônica Bonetti. Objetivação do Recurso Extraordinário: notável tendência?. In Revista Dialética de Direito Processual n.83.

. O Papel dos tribunais de Cúpula, a Missão do STF e a Repercussão Geral. In: De LUCCA, Newton; MEYER-PFLUG, Samantha Ribeiro. Direito Constitucional Contemporâneo - Homenagem ao Professor Michel Temer. São Paulo: Quartir Latin, 2012.

; MEYER-PFLUG, Samantha Ribeiro. Os mecanismos de contenção: repercussão geral e súmula vinculante e o acesso à justiça. In: XX Encontro Nacional do Conselho Nacional de Pesquisa e Pós Graduação em Direito CONPEDI, 2011, belo horizonte. XX Encontro Nacional do Conselho Nacional de Pesquisa e Pós Graduação em Direito CONPEDI. florianopolis: Fundação Boiteux, 2011. v. 1. pp. 266-384.

FUCK, Luciano Felício. O Supremo Tribunal federal e a repercussão geral. In: WAMBIER, Teresa Arruda Alvim (Coord.). Revista de Processo; ano 35, n.181; mar./2010.

MANCUSO, Rodolfo de Camargo. A realidade do judiciário brasileiro e os tribunais da federação: STJ e STF: inevitabilidade dos elementos de contenção dos recursos a eles dirigidos. In: Luiz Fux. Processo e Constituição: estudos em homenagem ao professor José Carlos Barbosa Moreira. RT, 2006.

MENDES, Gilmar; MEYER-PFLUG, Samantha. Passado e futuro da Súmula Vinculante. In: RENAULT, Sérgio Rabello Tamm. Reforma do Judiciário.SP: RT, 2005, pp.327-375.

OLIVEIRA, Guilherme José Braz de. Repercussão Geral das questões constitucionais e suas conseqüências para o julgamento do recurso extraordinário. Tese de doutorado, Faculdade de Direito do Largo Dão Francisco, 2009.

OTEIZA, Eduardo. A função das Cortes Supremas na América Latina. Revista de Processo n. 187, set.2010, pp. 181-230.

La Corte Suprema: entre la justicia sin política y la política sin justicia.

Libreria editora platense, 1994. 